\title{
Environmental unpredictability and stochasticity underlie dispersive movements of a terrestrial amphibian
}

\author{
Nathalie Jreidini ${ }^{1}$ and David Green ${ }^{1}$ \\ ${ }^{1}$ McGill University
}

March 10, 2022

\begin{abstract}
Dispersive movements are often thought to be multiclausal and driven by individual body size, sex, conspecific density, environmental variation and/or other factors. Yet such factors rarely account for most of the variation present among dispersive movements in nature, leaving open the possibility that dispersion might be indeterministic and vary in response to environmental stochasticity. We assessed the amount of variation in movement distances that could be accounted for by potential predictors of dispersal with a large empirical dataset of movement distances performed by Fowler's Toads (Anaxyrus fowleri) on the northern shore of Lake Erie at Long Point, Ontario (2002 - 2021, incl.). These toads are easy to sample repeatedly, can be identified individually and undertake dispersive movements parallel to the shoreline on a daily basis as they forage at night. Using a linear mixed-effect model that incorporated random effect terms to account for sampling variance and inter-year environmental variation, we found that all potential predictors of dispersive movements of these animals were, at best, weak predictors that accounted for virtually none of the variation observed among movement distances. We also used linear regression models to test for the impact of environmental stochasticity on dispersive movements and identified a strong positive correlation between the distribution of toad movement distances and variability in lake water level. We conclude that deterministic proximal factors, whether intrinsic or extrinsic, neither can be shown nor are necessary to drive dispersive movements in this population. Variation in dispersive movements can be ascribed, instead, to environmental unpredictability, consistent with nomadism.
\end{abstract}

\section{Introduction}

Dispersal, the one-way displacement of individual organisms leading to gene flow, is of central importance to population ecology and evolution (Marsh and Trenham 2001; Ronce 2007). On one hand, because dispersal is necessary for effects ranging from outbreeding to geographic range expansion, it is generally acknowledged as beneficial for most populations and therefore, with only rare exceptions, selectively advantageous (Hamilton and May 1977; Johnson and Gaines 1990; Parvinen et al. 2003; Poethke et al. 2003). On the other hand, dispersal by individuals away from habitable localities, without guarantee of finding another habitable site, is a highly risky endeavor, often with very low odds of success (Clobert et al. 2001; Stamps 2001; Cote and Clobert 2010; Bonte et al., 2019). This contradiction is a fundamental problem for understanding the ecology of dispersal. What drives individual organisms to disperse?

For many organisms, the answer to this question is straightforward - they have no say in whether they disperse or not. Propagules of sessile organisms, such as most plants, cannot occupy the same physical spaces as their parents and therefore must somehow disperse away. The seeds themselves are entirely passive when it comes to their own dispersal, and their dispersive trajectories may largely be stochastic (Nathan et al. 2011). Most animals, though, are motile at all life stages, and thus a variety of factors might exist to compel individuals to disperse under their own power (Bowler and Benton 2005; Matthysen 2012).

Many suggested drivers or predictors of dispersal are intrinsic properties of the animals themselves. Sexbiased dispersal, for instance, is widespread among animals and may be related to mating system (Greenwood 
1980) and/or the distribution of critical resources, such as nesting sites or potential mates (Li and Kokko 2019). However, if both sexes are equally affected by the distribution of resources, dispersal should not be sex-biased (Johnson and Gaines 1990) as seen in certain birds (Mäki-Petäys et al. 2007) and amphibians (Berven and Grudzien 1990; Trenham et al. 2001; Sinsch et al. 2012). Age and body size may also affect dispersal tendencies in that larger, older individuals may be able to move further than smaller individuals (Jenkins et al. 2007; Choi et al. 2003; Phillips et al. 2006) or, conversely, outcompete smaller individuals and so push them to move away (Bowler and Benton 2005).

There are other potential predictors of dispersal that are instead properties of the environment extrinsic to the individual animals. Conspecific density, leading to varying levels of intraspecific competition (Clobert et al. 2004; Bowler and Benton 2005; Ronce 2007; Baguette et al. 2011) may be positively correlated with dispersal in numerous fishes (Connor et al. 2013; Taylor et al. 2013), reptiles (Vignoli et al. 2012), birds (Pärn et al. 2012; Molina-Morales et al. 2012), or amphibians (Ousterhout and Semlitsch 2018). However, if living in groups is selectively advantageous, as seen in certain fruit flies (Betini et al. 2015), amphibians (Cayuela et al. 2019), mammals (Mabry 2014; Denomme-Brown et al. 2020), birds (Forero et al. 2002; McKellar et al. 2015; Fuentes et al. 2019), or reptiles (Calsbeek 2009), conspecific density can be negatively correlated with dispersal. Complicating matters further, sex-biased dispersal patterns may appear in response to density (De Bona et al. 2019; Scandolara et al. 2014; Fattebert et al. 2015), making density-dependent dispersal, to a certain extent, context dependent (Bocedi et al. 2012; Cayuela et al. 2018).

Landscape dynamics are also suggested to impact the dispersive movements of animals (Morales et al. 2010) but, unlike potential predictors, variation in landscape structure tends to affect the distribution of movement distances rather than their magnitude, as has been reported in Eurasian red squirrels, for example (Hämäläinen et al. 2019). Landscapes with little variation in either structure or resources should promote range residency and thus lead to a smaller range of movement distances, as seen in ungulate populations (Mueller et al. 2011). Alternatively, unpredictability in environmental trends leads to unpredictability in dispersive movement trends. As such, irregular movements that are difficult to predict and are neither migratory nor philopatric have been referred to as nomadic and have been associated with environments that are highly variable, both spatially and temporally (Jonzén et al. 2011; Mueller et al. 2011).

Nomadism is either characterized by stochasticity in movement paths (e.g., Schwarzkopf and Alford 2002) or, more often, by temporal stochasticity in the distribution of movement distances in response to landscape unpredictability (Mueller and Fagan 2008; Jonzén et al. 2011; Singh et al. 2012). Unpredictable environmental variation promotes indeterministic nomadic movements in a manner similar to how seasonal variation in resource availability promotes migration (Jonzén et al. 2011). Nomadism remains poorly documented because the irregular and wide-ranging movements of nomadic animals are difficult to track (Runge et al. 2015), and identifying it requires long-term datasets to capture temporal variation in movement distances (Teitelbaum and Mueller 2019).

Amphibians can offer several advantages over many other types of animals for studying movement dynamics. Even their largest movements are relatively small enough to be readily detectable (Smith and Green 2005) and numerous amphibian populations are amenable to being monitored in long-term studies over many consecutive years (e.g., Sinsch 2014; Cayuela et al. 2020). In particular, the Fowler's Toads (Anaxyrus fowleri ) found at Long Point, Ontario, a $35 \mathrm{~km}$ long sand spit on the northern shore of Lake Erie, represent a study system that is especially well-suited for investigating dispersive movements in relation to environmental unpredictability and potential predictors of dispersal (Smith and Green 2006). The movements made by these toads are almost entirely restricted to a sandy beach running east-west, parallel to the lakeshore, making such movements essentially one-dimensional and potentially subject to variations in lake water level that can alter the extent and structure of the beach. Furthermore, the toads are easily and repeatably captured while they are active at night and are readily identifiable as individuals (Schoen et al. 2015), making it possible to amass a large dataset of individualized movement distances. If any particular predictors are responsible for the dispersive movements made by these toads, then they should account for significant amounts of the variation seen in the toads' movement distances. Alternatively, if the toads are nomadic, then 
environmental variation should be of greater significance than any potential proximal predictors, whether intrinsic or extrinsic. Finally, if none of these factors significantly influence the toads' movements, then the observed pattern of dispersion may be stochastic.

\section{Methods}

\section{Data collection and study system.}

We used the dataset of geo-referenced captures of individually identified toads amassed by Smith and Green (2006) over 4 years (2002 - 2005, incl.) and augmented it with equivalent data gathered over a further 16 years (2006 - 2021, incl.). The study site was an $8.3 \mathrm{~km}$ stretch of shoreline consisting of beach, dunes, marshlands, and areas of settlement (Smith and Green 2005; Greenberg and Green 2013). Unlike previous surveys of this species (Smith and Green 2006), we did not toe-clip animals for identification. Instead, we identified individuals based on their unique patterns of dorsal spots in photographs (Schoen et al. 2015), which enabled us to assign every individual, including juveniles, a unique identity number and track them throughout the active season and from year to year.

We used the UTM geo-coordinates to calculate Euclidean distances, in meters, between successive encounters of individual toads on the beach. In our analyses, we did not consider springtime migratory movements made by adult toads to or from breeding sites off the beach (Marchand et al. 2017). We calculated movement distances irrespective of their directionality, eastward or westward. To derive a measure of the toads' density on any given occasion, we also used the UTM geo-coordinates to calculate nearest-neighbor distance between individual toads active on the same night.

We obtained daily average and monthly maximum data on Lake Erie water levels, in meters above mean sea level, from the website of the US Army Corps of Engineers, Detroit District (https://www.lre.usace.army.mil/) and daily weather conditions (total daily precipitation, in millimeters, and daily average air temperature, in ${ }^{\circ} \mathrm{C}$ ) from the Environment Canada website (https://climate.weather.gc.ca/) for the Port Colborne, Ontario, weather station. We also collected air temperature data using a handheld digital thermometer during surveys (Green 2017). We used standard deviation, $\sigma$, as the measure of variation over the whole year in these three environmental variables, as well as in animal movement distances.

\section{Analysis}

The response variable, movement distances, was $\log _{10}$-transformed in all analyses to eliminate heteroscedasticity. We first used movement distances measured over varying lag times (i.e., time elapsed between encounters) to explore whether distances and time are correlated using ANOVA. If they are, then the subsequent analyses would only be carried out using the subset of daily movement distances made over $24 \mathrm{hrs}$ to overcome any biases resulting from variation in elapsed time between successive encounters (Gamble et al. 2007; Blouin-Demers and Weatherhead 2020).

We used linear mixed-effect models (LMMs) to assess the impact of intrinsic and extrinsic predictors on movement distances performed by the toads. Random effect terms year and individual (the individual identities of the animals) were included in all LMMs to account for inter-annual and inter-individual sampling variance, respectively.

As A. fowleri are size-dimorphic, with female adults larger than both male adults and juveniles, we used both ANOVA and LMM to test for a sex-bias with a subset of the dataset to include adult males and adult females of the same size. Similarly, we tested for an age-bias with a subset of the dataset to include adult males and juveniles of the same size, as adult female and juvenile sizes do not overlap. Depending upon the results, the intrinsic categorical term, sex, which included both sexually mature adults as well as pre-sexual juveniles, was added to the LMM as an interaction term with continuous term body size .

Extrinsic, continuous terms were nearest-neighbor distance $\left(\log _{10}\right.$-transformed), air temperature (measured at each toad encounter), precipitation (total daily rainfall), andlake level (maximum daily water level). Desiccation risk was not deemed worth investigating as individuals of this population have unrestricted 
access to the lake for hydration. We obtained parameter estimates using maximum likelihood with the Laplace approximation method (Bates et al. 2020). We inferred the intraclass correlation coefficient (ICC) to explore whether movement distances were nested per year and/or pre individual.

We tested for variation in distribution of movement distances between years using ANOVA, then subsequently tested whether environmental variation affected the annual distribution of movement distances using a linear regression model with annual standard deviation in movement distances as the response variable and annual standard deviation in the environmental variables, air temperature (average daily ambient temperature), precipitation (total daily rainfall), andlake level (maximum monthly water level), as predictor terms.

Different combinations of predictors for all models were compared using Akaike Information Criterion (AIC) to determine the model that explains the greatest amount of variation in the response variable using the fewest number of independent variables, deemed the best-fit model (Burnham and Anderson 2004). $R^{2}$ values as coefficients of determination were used in linear regressions and in LMMs as marginal $R^{2}$ and conditional $R^{2}$ values to account for the amount of variation accounted for by predictors and by random effect terms, respectively (Nakagawa and Schielzeth 2013).

All statistical analyses and visualizations were done in $\mathrm{R}$ version 3.6.3 ( $\mathrm{R}$ Core Team 2021). LMMs were conducted and explored using R packages 'lme4' (Bates et al. 2020) and 'MuMIn' (Bartoń 2020).

\section{Results}

We amassed a dataset of 6,279 movement distances for 1,441 individual toads over 20 years (2002 - 2021, incl), with lag times ranging from 1 to 86 days with a median distance of $60.64 \mathrm{~m}$. As is invariably the case for dispersal data (Fraser et al. 2001; Smith and Green 2006), the frequency distribution of these movement distances was left-skewed and leptokurtic (Fig. 1a). The correlation between normalized movement distances (Fig. 1b) and $\log _{10}$-transformed lag time had little explanatory power $\left(R^{2}=0.032\right)$ but was highly significant (ANOVA: $F_{1,6277}=211.1, P<0.001$ ) (Fig. 1c), justifying our reduction of the dataset to include only daily movement distances and thereby eliminate the influence of lag time from subsequent analyses. The reduced dataset we used for analysis consisted of 1,378 daily movement distances for 714 individuals (279 adult females, 167 adult males and 325 juveniles). The median movement distance was $\mathrm{x}=49.65 \mathrm{~m}$, with movements of females averaging slightly farther $(\mathrm{x}=55.04 \mathrm{~m})$ than those of either males $(\mathrm{x}=50.22 \mathrm{~m})$ or juveniles $(\mathrm{x}=41.23 \mathrm{~m})$.

Body size differed greatly between groups (ANOVA: $F_{2,6276}=6227, P<0.001, R^{2}=0.665$ ), with adult females on average larger $(\mathrm{x}=65.32 \mathrm{~mm})$ than adult males $(\mathrm{x}=57.94 \mathrm{~mm})$, and both adult sexes larger than sexually immature juveniles $(\mathrm{x}=45.54 \mathrm{~mm})$. However, we found daily movement distances to be neither sex-biased nor age-biased. The difference in movement distances between adult males and adult females of the same size range $\left(55-75 \mathrm{~mm}\right.$ ) was not significant (ANOVA: $F_{2,733}=2.42, P=0.090, R^{2}=0.004$ ), even when accounting for random effect terms year and individual (LMM:Estimate $=0.014, S E=0.010, t$ $=1.451, P=0.147)$. Likewise, the difference in movement distances between adult males and juveniles of the same size range ( $40-55 \mathrm{~mm}$ ) was also not significant (ANOVA: $F_{1,475}=0.038, P=0.847, R^{2}=0.002$; LMM: Estimate $=-0.0001, S E=0.015, t=-0.059, P=0.953)$. Sex and age were therefore removed from subsequent analyses.

The variation in movement distances accounted for by all predictors was negligible, according to marginal $R^{2}$ values, but random effect terms year and individual accounted for a small portion of the variation in movement distances, according to conditional $R^{2}$ values (Table 1). The best-fit LMM according to AIC values included predictors body size and $\log _{10}$-transformed nearest-neighbor distance (marginal $R^{2}=$ 0.014 ; conditional $R^{2}=0.194$ ) (Table 1). Correlation estimates were all negligeable in the full LMM as well, although body sizeand nearest-neighbor distance were found to be significant yet weak predictors of movement distances (Table 2).

Most of the variation in movement distances performed by the toads was unaccounted for by neither the predictors nor the random effect terms, combined (Table 1). Moreover, the intraclass correlation coefficient 
was low $(\mathrm{ICC}=0.19)$, suggesting that the variation in movement distances is not significantly nested neither per year nor per individual.

The distribution of daily movement distances varied significantly between years (ANOVA: $F$ 1, $1378=5.098$, $P=0.024)$ although year alone had little explanatory power $\left(R^{2}=0.030\right)$ (Fig. 2a). The best-fit linear regression model according to AIC values included annual standard deviations in lake level and in air temperature (Table 1) and was used to obtain regression fit values $\left(R^{2}=0.360\right)$ (Fig. 2b). The variation in annual standard deviation in daily movement distances accounted for by all environmental variables was substantial $\left(R^{2}=0.386\right)$ (Table 1$)$.

In the full linear regression model, annual standard deviation in daily movement distances was significantly, and positively, correlated with annual standard deviation in lake level across individuals, but was weakly, and negatively, correlated with annual standard deviation inair temperature and not correlated at all with annual standard deviation in precipitation (Table 3).

\section{Discussion}

Our results demonstrate that $A$. fowleri dispersive movements are not necessarily driven by either intrinsic or extrinsic factors. The daily movement distances of these toads are neither sex-biased, age-biased, size-biased, density-dependent, nor correlated with environmental variables such as air temperature, precipitation, or lake water level, at a daily scale. The predictors are too weakly correlated with movement distances in these animals to be biologically meaningful as they account for effectively none of the variation in distances moved. The apparent statistical significance of body size andnearest-neighbor distance is largely the result of the statistical power of our very large dataset. Random effect terms, though, did account for some of the variation in daily movement distances that could arise due to sampling bias from resampling the same individuals and from annual changes in survey effort. The fine temporal and spatial scale of our measured movement distances, occurring over $24 \mathrm{hrs}$ and confined to east-west directions, left little room for noise in overall trajectory.

Just like Smith and Green (2006), we find no evidence for sex bias in movement distances among adult toads, indicating that mating system may be insufficient to explain variation in dispersive tendencies (Helfer et al. 2012). In sexually size-dimorphic species, such as most anuran amphibians (Kupfer 2007), it can be difficult to distinguish between sex-biased and size-biased dispersal patterns. Although A. fowleri adult females are larger than adult males (and larger than juveniles), the impact of body size is nonetheless not a significant predictor of distances moved.

There is also no evidence for juvenile-biased dispersal in A. fowleri, although the juvenile stage is often suggested to constitute the dispersive stage particularly in amphibians (e.g., Dole 1971; Baker 1978; Greenwood 1980; Breden 1987; Kupfer and Kneitz 2000). The perception of juveniles as the dispersive stage in some systems might arise as an artifact of the larger abundance of juveniles present in the population, as concluded by Smith and Green (2005). But we continue to find no trace of juvenile-biased dispersal even when considering individual variance as a random effect term.

The relationship between density and dispersal is complex, and possibly non-linear. Density-dependence might only be apparent above a density threshold (Baines et al. 2014) or might switch from a negative to a positive correlation past a certain point (Kim et al. 2009; Fattebert et al. 2015). Testing for a density threshold has not yet been documented in amphibians, but the abundance of $A$. fowleri at Long Point varies (Greenberg \& Green 2013) and lately has been low (unpublished). Thus, using nearest-neighbour distance as a proxy for conspecific density does not allow us to dismiss the possibility that higher densities might impact their dispersive movements.

As short-scale movements made by $A$. fowleri between refuge sites turn into dispersive movements over larger temporal and spatial scales (Marchand et al. 2017), and none of the tested predictors were found to account for the variation in movement distances, dispersal in these toads can occur independently of their possible influence. The movements may instead be fundamentally stochastic, and the animals nomadic as a 
result, whereby the distribution of movement distances varies, at least partially, according to the variation in landscape or habitat structure. As these animals are capable of true navigation as they home from unfamiliar sites (manuscript in review), their stochastic movement trends cannot be the result of a lack of spatial orientation.

Nomadism should either occur when maintaining a home range is not advantageous, or when moving frequently is advantageous and moving to new sites is not costly (Sinclair 1983). Over the past 20 years, Lake Erie water levels have been highly variable and have lately been at historic highs, in line with trends recorded in the other Great Lakes (Gronewold and Rood 2019). A higher water level translates to a narrower beach shore and a disrupted dune structure in the Long Point landscape. The positive correlation we observe between variation in lake level and variation in the toads' movement distances on an annual basis is consistent with a hypothesis that environmental unpredictability resulting from stochastic landscape changes will influence animals' dispersive movement distances. This finding that dispersion patterns can shift with shifting landscape structure is characteristic of nomadic movements (Mueller and Fagan 2008; Jonzén et al. 2011).

There exists a conceptual gap between the fields of animal movement ecology and animal dispersal concerning dispersive movements. In the movement ecology literature, individual movements are generally proposed to be governed by random effects (Hanski 1999; Antman et al. 2001; Tilman and Kareiva 2018) whereas, in the animal dispersal literature, dispersive movements are commonly considered to be determined by drivers or predictors (Clobert and Rousset 2004; Matthysen 2012; Denomme-Brown et al. 2020). The Fowler's Toads at Long Point, Ontario, disperse widely but are not demonstrably driven to do so (Smith and Green 2006; Marchand et al. 2017). Yet the magnitudes of their movements are correlated with an extrinsic, stochastic factor influencing their habitat: lake level. In this regard, the concept of nomadism can bridge the gap between the animals' indeterministic short-scale daily movement distances and their stochastic large-scale dispersal. Our results from studying a very simple system of small amphibians moving at will to and fro along a lakeshore do not exclude the possibility that dispersal in other organisms in other environments may be significantly driven by any combination of internal and/or external factors. We do show, however, that this need not necessarily always be true.

\section{References}

Antman, S. S., Marsden, J. E., Sirovich, L., Wiggins, S. (Eds) (2001). The basics of diffusion. In Diffusion and ecological problems: Modern perspectives (Vol 14) (pp. 10-30). Springer, New York, NY.

Baguette, M., Clobert, J., and Schtickzelle, N. (2011). Metapopulation dynamics of the bog fritillary butterfly: experimental changes in habitat quality induced negative density-dependent dispersal. Ecography , 34 (1), 170-176.

Baines, C. B., McCauley, S. J., and Rowe, L. (2014). The interactive effects of competition and predation risk on dispersal in an insect. Biology letters , 10 (6), 20140287.

Baker, R. (1978). Evolutionary ecology of animal migration. Holmes \& Meier Publishers.

Bartoń, K. (2020). MuMIn: Multi-Model Inference. $-<$ https://cran.r-project.org/package=MuMIn $>$.

Bates, D., Maechler, M., Bolker, B., Walker, S., Christensen, R. H. B., Singmann, H., ... and Scheipl, F. (2020). lme4: Linear Mixed-Effects Models using 'Eigen' and S4. $\quad$ - <https://cran.rproject.org $/$ package $=$ lme $4>$.

Berven, K. A., and Grudzien, T. A. (1990). Dispersal in the wood frog (Rana sylvatica ): implications for genetic population structure. Evolution , 44 (8), 2047-2056.

Betini, G. S., Pardy, A., Griswold, C. K., and Norris, D. R. (2015). The role of seasonality and non-lethal carry-over effects on density-dependent dispersal. Ecosphere, 6 (12), 1-9. 
Bhattacharya, C. G. (1967). A simple method of resolution of a distribution into Gaussian components. Biometrics , 115-135.

Blouin-Demers, G., and Weatherhead, P. J. (2021). Dispersal by gray ratsnakes: Effects of sex, age and time. Population Ecology, 63 (2), 145-151.

Bocedi, G., Heinonen, J., and Travis, J. M. (2012). Uncertainty and the role of information acquisition in the evolution of context-dependent emigration. The American Naturalist , 179 (5), 606-620.

Bonte, D., Van Dyck, H., Bullock, J. M., Coulon, A., Delgado, M., Gibbs, M., Lehouck,V., Matthysen, E., Mustin,K., Saastamoinen,M., Schtickzelle, N., Stevens, V. M., Vandewoestijne, S., Baguette, M., Barton, K., et al. (2012). Costs of dispersal. Biological Reviews (87), 290-312.

Bowler, D. E., and Benton, T. G. (2005). Causes and consequences of animal dispersal strategies: relating individual behaviour to spatial dynamics. Biological Reviews , 80 (2), 205-225.

Breden, F. (1987). The effect of post-metamorphic dispersal on the population genetic structure of Fowler's toad, Bufo woodhousei fowleri . Copeia , (2), 386-395.

Burnham, K. P., \& Anderson, D. R. (2004). Multimodel inference: understanding AIC and BIC in model selection. Sociological methods \& research, 33 (2), 261-304.

Calsbeek, R. (2009). Sex-specific adult dispersal and its selective consequences in the brown anole, Anolis sagrei . Journal of Animal Ecology , 78 (3), 617-624.

Cayuela, H., Grolet, O., and Joly, P. (2018). Context-dependent dispersal, public information, and heterospecific attraction in newts. Oecologia , 188 (4), 1069-1080.

Cayuela, H., Schmidt, B. R., Weinbach, A., Besnard, A., and Joly, P. (2019). Multiple density-dependent processes shape the dynamics of a spatially structured amphibian population. Journal of Animal Ecology , 88 (1), 164-177.

Cayuela, H., Valenzuela-Sánchez, A., Teulier, L., Martínez-Solano, Í., Léna, J.P., Merilä, J., Muths, E., Shine, R., Quay, L., Denoël, M. and Clobert, J., (2020). Determinants and consequences of dispersal in vertebrates with complex life cycles: a review of pond-breeding amphibians. The Quarterly Review of Biology, 95(1), $1-36$.

Choi, I., Shim, J. H., and Ricklefs, R. E. (2003). Morphometric relationships of take-off speed in anuran amphibians. Journal of Experimental Zoology Part A: Comparative Experimental Biology, 299 (2), 99-102.

Clobert, J., E. Danchin, A. A. Dhondt, and J. D. Nichols. (2001). Dispersal. Oxford University Press, New York, New York, USA.

Clobert, J., Ims, R. A., and Rousset, F. (2004). Causes, mechanisms and consequences of dispersal. In Ecology, genetics and evolution of metapopulations (pp. 307-335). Academic Press.

Connor, W. P., Tiffan, K. F., Plumb, J. M., and Moffitt, C. M. (2013). Evidence for density-dependent changes in growth, downstream movement, and size of Chinook Salmon subyearlings in a large-river landscape. Transactions of the American Fisheries Society, 142 (5), 1453-1468.

Cote, J., and Clobert, J. (2010). Risky dispersal: avoiding kin competition despite uncertainty. Ecology , 91 (5), 1485-1493.

De Bona, S., Bruneaux, M., Lee, A. E., Reznick, D. N., Bentzen, P., and Lopez-Sepulcre, A. (2019). Spatiotemporal dynamics of density-dependent dispersal during a population colonisation. Ecology letters, 22 (4), 634-644.

Denomme-Brown, S. T., Cottenie, K., Falls, J. B., Falls, E. A., Brooks, R. J., and McAdam, A. G. (2020). Variation in space and time: a long-term examination of density-dependent dispersal in a woodland rodent. Oecologia , 193 (4), 903-912. 
Dole, J. W. (1971). Dispersal of recently metamorphosed leopard frogs, Rana pipiens . Copeia, 221-228.

Fattebert, J., Balme, G., Dickerson, T., Slotow, R., and Hunter, L. (2015). Density-dependent natal dispersal patterns in a leopard population recovering from over-harvest. PloS one , 10 (4), e0122355.

Forero, M. G., Donazar, J. A., and Hiraldo, F. (2002). Causes and fitness consequences of natal dispersal in a population of black kites. Ecology , 83 (3), 858-872.

Fraser, D. F., Gilliam, J. F., Daley, M. J., Le, A. N., and Skalski, G. T. (2001). Explaining leptokurtic movement distributions: intrapopulation variation in boldness and exploration. The American Naturalist , 158 (2), 124-135.

Fuentes, D., Rubalcaba, J. G., Veiga, J. P., and Polo, V. (2019). Long-term fitness consequences of breeding density in starling colonies: an observational approach. Journal of Ornithology , 160 (4), 1035-1042.

Gamble, L. R., McGarigal, K., and Compton, B. W. (2007). Fidelity and dispersal in the pond-breeding amphibian, Ambystoma opacum : implications for spatio-temporal population dynamics and conservation. $B i$ ological Conservation , 139 (3-4), 247-257.

Gayanilo, F. C., Sparre, P., and Pauly, D. (2005). FAO-ICLARM stock assessment tools II: User's guide (No. 8). Food \& Agriculture Org.

Green, D. M. (2017). Amphibian breeding phenology trends under climate change: predicting the past to forecast the future. Global change biology , 23 (2), 646-656.

Greenberg, D. A., and Green, D. M. (2013). Effects of an invasive plant on population dynamics in toads. Conservation Biology , 27 (5), 1049-1057.

Greenwood, P. J. (1980). Mating systems, philopatry and dispersal in birds and mammals. Animal behaviour , 28 (4), 1140-1162.

Gronewold, A. D., and Rood, R. B. (2019). Recent water level changes across Earth's largest lake system and implications for future variability. Journal of Great Lakes Research , 45 (1), 1-3.

Hamalainen, S., Fey, K., \& Selonen, V. (2019). The effect of landscape structure on dispersal distances of the Eurasian red squirrel. Ecology and evolution , 9 (3), 1173-1181.

Hamilton, W. D., and May, R. M. (1977). Dispersal in stable habitats. Nature , 269 (5629), 578-581.

Hanski, I. (1999). Habitat connectivity, habitat continuity, and metapopulations in dynamic landscapes. Oikos , 209-219.

Helfer, V., Broquet, T., and Fumagalli, L. (2012). Sex-specific estimates of dispersal show female philopatry and male dispersal in a promiscuous amphibian, the alpine salamander (Salamandra atra ). Molecular Ecology , 21 (19), 4706-4720.

Jenkins, D. G., Brescacin, C. R., Duxbury, C. V., Elliott, J. A., Evans, J. A., Grablow, K. R., ... and Pepe, D. (2007). Does size matter for dispersal distance? Global Ecology and Biogeography , 16 (4), 415-425.

Johnson, M. L., and Gaines, M. S. (1990). Evolution of dispersal: theoretical models and empirical tests using birds and mammals. Annual review of ecology and systematics , 21 (1), 449-480.

Jonzen, N., Knudsen, E., Holt, R. D., and Saether, B. E. (2011). Uncertainty and predictability: the niches of migrants and nomads.Animal migration: a synthesis , 91, 109.

Kim, S. Y., Torres, R., and Drummond, H. (2009). Simultaneous positive and negative density dependent dispersal in a colonial bird species. Ecology , 90 (1), 230-239.

Kupfer, A. (2007). Sexual size dimorphism in amphibians: an overview. Sex, size and gender roles: evolutionary studies of sexual size dimorphism , $5,50-60$. 
Kupfer, A., and Kneitz, S. (2000). Population ecology of the great crested newt (Triturus cristatus ) in an agricultural landscape: dynamics, pond fidelity and dispersal. Herpetological Journal , 10 (4), 165-171.

Li, X.Y. and Kokko, H., 2019. Sex-biased dispersal: A review of the theory. Biological Reviews, 94(2), pp.721-736.

Mabry, K. E. (2014). Effects of sex and population density on dispersal and spatial genetic structure in brush mice. Journal of Mammalogy , 95 (5), 981-991.

Maki-Petays, H., Corander, J., Aalto, J., Liukkonen, T., Helle, P., and Orell, M. (2007). No genetic evidence of sex-biased dispersal in a lekking bird, the capercaillie (Tetrao urogallus). Journal of evolutionary biology , 20 (3), 865-873.

Marchand, P., Boenke, M., and Green, D. M. (2017). A stochastic movement model reproduces patterns of site fidelity and long-distance dispersal in a population of Fowler's toads (Anaxyrus fowleri ). Ecological Modelling , 360 , 63-69.

Marsh, D. M., and Trenham, P. C. (2001). Metapopulation dynamics and amphibian conservation. Conservation biology, 15 (1), 40-49.

Matthysen, E. (2012). Multicausality of dispersal: a review. Dispersal ecology and evolution, 27, 3-18.

McKellar, A. E., Reudink, M. W., Marra, P. P., Ratcliffe, L. M., and Wilson, S. (2015). Climate and density influence annual survival and movement in a migratory songbird. Ecology and evolution , 5 (24), 5892-5904.

Middleton, J., and Green, D. M. (2015). Adult age-structure variability in an amphibian in relation to population decline. Herpetologica, 71 (3), 190-195.

Molina-Morales, M., Martinez, J. G., and Aviles, J. M. (2012). Factors affecting natal and breeding magpie dispersal in a population parasitized by the great spotted cuckoo. Animal Behaviour , 83 (3), 671-680.

Morales, J. M., Moorcroft, P. R., Matthiopoulos, J., Frair, J. L., Kie, J. G., Powell, R. A., .. \& Haydon, D. T. (2010). Building the bridge between animal movement and population dynamics. Philosophical Transactions of the Royal Society B: Biological Sciences , 365 (1550), 2289-2301.

Mueller, T., and Fagan, W. F. (2008). Search and navigation in dynamic environments-from individual behaviors to population distributions. Oikos , 117 (5), 654-664.

Mueller, T., Olson, K. A., Dressler, G., Leimgruber, P., Fuller, T. K., Nicolson, C., ... and Fagan, W. F. (2011). How landscape dynamics link individual-to population-level movement patterns: a multispecies comparison of ungulate relocation data. Global Ecology and Biogeography , 20 (5), 683-694.

Nakagawa, S., and Schielzeth, H. (2013). A general and simple method for obtaining $\mathrm{R}^{2}$ from generalized linear mixed-effects models. Methods in ecology and evolution , 4 (2), 133-142.

Nathan, R., Katul, G. G., Bohrer, G., Kuparinen, A., Soons, M. B., Thompson, S. E., .. and Horn, H. S. (2011). Mechanistic models of seed dispersal by wind. Theoretical Ecology , 4 (2), 113-132.

Ousterhout, B. H., and Semlitsch, R. D. (2018). Effects of conditionally expressed phenotypes and environment on amphibian dispersal in nature. Oikos , 127 (8), 1142-1151.

Parn, H., Ringsby, T. H., Jensen, H., and Saether, B. E. (2012). Spatial heterogeneity in the effects of climate and density-dependence on dispersal in a house sparrow metapopulation. Proceedings of the Royal Society B: Biological Sciences , 279 (1726), 144-152.

Parvinen, K., Dieckmann, U., Gyllenberg, M., and Metz, J. A. (2003). Evolution of dispersal in metapopulations with local density dependence and demographic stochasticity. Journal of Evolutionary Biology , 16 (1), 143-153. 
Phillips, B. L., Brown, G. P., Webb, J. K., and Shine, R. (2006). Invasion and the evolution of speed in toads. Nature, 439 (7078), 803.

Poethke, H. J., Hovestadt, T., and Mitesser, O. (2003). Local extinction and the evolution of dispersal rates: causes and correlations. The American Naturalist, 161 (4), 631-640.

R Core Team (2021). R: A language and environment for statistical computing. R foundation for Statistical Computing, Vienna, Austria. URL http://www.R-project.org/.

Ronce, O. (2007). How does it feel to be like a rolling stone? Ten questions about dispersal evolution. Annu. Rev. Ecol. Evol. Syst. , $38,231-253$.

Runge, C. A., Tulloch, A., Hammill, E., Possingham, H. P., and Fuller, R. A. (2015). Geographic range size and extinction risk assessment in nomadic species. Conservation Biology , 29 (3), 865-876.

Scandolara, C., Lardelli, R., Sgarbi, G., Caprioli, M., Ambrosini, R., Rubolini, D., and Saino, N. (2014). Context-, phenotype-, and kin-dependent natal dispersal of barn swallows (Hirundo rustica). Behavioral Ecology , 25 (1), 180-190.

Schoen, A., Boenke, M., and Green, D. M. (2015). Tracking toads using photo identification and imagerecognition software. Herpetological Review , 46 (2), 188-192.

Schwarzkopf, L., and Alford, R. A. (2002). Nomadic movement in tropical toads. Oikos , 96 (3), 492-506.

Sinclair, A. R. E. (1983). The function of distance movements in vertebrates. The ecology of animal movement , 248-258.

Singh, N. J., Borger, L., Dettki, H., Bunnefeld, N., and Ericsson, G. (2012). From migration to nomadism: movement variability in a northern ungulate across its latitudinal range. Ecological Applications , 22 (7), 2007-2020.

Sinsch, U. (2014). Movement ecology of amphibians: from individual migratory behaviour to spatially structured populations in heterogeneous landscapes. Canadian Journal of Zoology, 92(6) , 491-502.

Sinsch, U., Oromi, N., Miaud, C., Denton, J., and Sanuy, D. (2012). Connectivity of local amphibian populations: modelling the migratory capacity of radio-tracked natterjack toads. Animal Conservation , 15 (4), 388-396.

Smith, M. A., and Green, D. M. (2005). Dispersal and the metapopulation paradigm in amphibian ecology and conservation: are all amphibian populations metapopulations? Ecography , 28 (1), 110-128.

Smith, M. A., and Green, D. M. (2006). Sex, isolation and fidelity: unbiased long-distance dispersal in a terrestrial amphibian. Ecography, 29 (5), 649-658.

Stamps, J. A. (2001). Habitat selection by dispersers: integrating proximate and ultimate approaches. Pages 110-122 in J. Clobert, E. Danchin, A. A. Dhondt, and J. D. Nichols, editors. Dispersal. Oxford University Press, New York, New York, USA.

Taylor, M. D., Fairfax, A. V., and Suthers, I. M. (2013). The race for space: Using acoustic telemetry to understand density-dependent emigration and habitat selection in a released predatory fish. Reviews in Fisheries Science, 21 (3-4), 276-285.

Teitelbaum, C. S., and Mueller, T. (2019). Beyond migration: causes and consequences of nomadic animal movements. Trends in Ecology $8 \mathcal{G}$ Evolution , 34 (6), 569-581.

Tilman, D., and Kareiva, P. (Eds.). (2018). Spatial ecology: the role of space in population dynamics and interspecific interactions (MPB-30) (Vol. 30). Princeton University Press.

Trenham, P. C., Koenig, W. D., and Shaffer, H. B. (2001). Spatially autocorrelated demography and interpond dispersal in the salamander Ambystoma californiense . Ecology , 82 (12), 3519-3530. 
Vignoli, L., Vuerich, V., and Bologna, M. A. (2012). Experimental study of dispersal behaviour in a wall lizard species (Podarcis sicula) (Sauria Lacertidae). Ethology Ecology E Evolution, 24 (3), 244-256.

Table 1: Comparison of explanatory linear mixed-effect models (LMMs) for $\log _{10}$-transformed daily movement distances $(n=1,378)$ and explanatory linear regression models for the annual standard deviation of $\log _{10}$-transformed daily movement distances $(n=20)$ performed by Fowler's Toads, Anaxyrus fowleri $(N$ $=714)$, at Long Point, Ontario (2002 - 2021, incl). Air temperature corresponds to the ambient temperature measured at that encounter, precipitation corresponds to the total daily rainfall, and lake level corresponds to the average daily water level. $\sigma_{\text {air temperature }}$ corresponds to the annual standard deviation in mean daily ambient temperature, $\sigma_{\text {precipitation }}$ corresponds to the annual standard deviation in total daily rainfall, and $\sigma_{\text {lake level }}$ corresponds to the annual standard deviation in monthly maximum lake level. Models are presented in order of decreasing information content as evaluated using $\Delta \mathrm{AIC}$ for model fit. Chi-square $\left(\chi^{2}\right)$ likelihood ratio tests results are reported for each model. Only models that were a better fit than the null model are reported. All LMMs include random effect termsyear and individual. Marginal $R^{2}$ values correspond to the variation in the response variable explained by predictors alone, whereas conditional $R^{2}$ values correspond to the variation explained by both predictors and random effect terms and is only reported for LMMs.

\begin{tabular}{lll}
\hline Response variable & Model & Model \\
\hline No. & No. & Fixed effect terms (predictors) \\
$\log _{10}$ (movement distances $)$ & 1 & Body size $+\log _{10}$ (nearest-neighbor distance $)$ \\
& 2 & Body size \\
& 3 & Body size $+\log _{10}($ nearest-neighbor distance $)+$ Air temperature + Precipitation + La \\
& 4 & $\log _{10}($ nearest-neighbor distance $)$ \\
null & null & - \\
$\sigma_{\log _{10}(\text { movement distances })}$ & 1 & $\sigma_{\text {air temperature }}+\sigma_{\text {lake level }}$ \\
& 2 & $\sigma_{\text {lake level }}$ \\
& 3 & $\sigma_{\text {air temperature }}+\sigma_{\text {lake level }}+\sigma_{\text {precipitation }}$ \\
null & null & \\
\hline
\end{tabular}

*Statistically significant at $\alpha=0.05$

**Statistically significant at $\alpha=0.01$

Table 2: LMM coefficients for the full models for $\log _{10}$-transformed daily movement distances $(n=1,378)$ performed by Fowler's Toads, Anaxyrus fowleri $(N=714)$, at Long Point, Ontario (2002 - 2021, incl). Air temperature corresponds to the ambient temperature measured at that encounter, precipitation corresponds to the total daily rainfall, and lake level corresponds to the average daily water level.

\begin{tabular}{lllll}
\hline Predictor & Estimate & CI + & $t$ & $P$ \\
\hline Intercept (full model) & 6.755 & $-78.054-91.563$ & 0.156 & 0.876 \\
Body size & $\mathbf{0 . 0 1 0}$ & $\mathbf{0 . 0 0 4}-\mathbf{0 . 1 6 8}$ & $\mathbf{3 . 0 6 9}$ & $\mathbf{0 . 0 0 2 * *}$ \\
$\log _{\mathbf{1 0}}$ (nearest-neighbor distance) & $\mathbf{0 . 0 2 0}$ & $\mathbf{0 . 0 0 4}-\mathbf{0 . 3 5 7}$ & $\mathbf{2 . 5 1 7}$ & $\mathbf{0 . 0 1 2}^{*}$ \\
Air temperature & -0.005 & $-0.033-0.023$ & -0.374 & 0.708 \\
Precipitation & -0.005 & $-0.019-0.009$ & -0.675 & 0.499 \\
Lake level & -0.019 & $-0.506-0.468$ & -0.077 & 0.939 \\
\hline
\end{tabular}

$+2.5 \%-97.5 \%$ confidence intervals.

*Statistically significant at $\alpha=0.05$ 
**Statistically significant at $\alpha=0.01$

Table 3 : Linear regression results for within-year variation in daily movement distances performed by Fowler's Toads, Anaxyrus fowleri, at Long Point, Ontario, modeled as the annual standard deviation $(\sigma)$ in $\log _{10}$-tranformed movement distances, against the annual standard deviation in environmental variables:lake level (monthly maximum), air temperature (daily average), and precipitation (daily total), over $n=20$ years, $2002-2021$ (incl.).

\begin{tabular}{lllll}
\hline Environmental variable & Estimate & CI+ & $t$ & $P$ \\
\hline Intercept (full model) & 2.212 & $0.080-4.344$ & 2.199 & $0.043^{*}$ \\
$\sigma_{\text {lake level }}$ & $\mathbf{0 . 7 8 5}$ & $\mathbf{0 . 1 0 5}-\mathbf{1 . 4 6 4}$ & $\mathbf{2 . 4 7 7}$ & $\mathbf{0 . 0 2 6}$ \\
$\sigma_{\text {air temperature }}$ & -0.155 & $-0.353-0.043$ & -1.656 & 0.117 \\
$\sigma_{\text {precipitation }}$ & 0.022 & $-0.034-0.079$ & 0.834 & 0.417 \\
\hline
\end{tabular}

$+2.5 \%-97.5 \%$ confidence intervals.

*Statistically significant at $\alpha=0.05$

\section{Figure legends}

Figure 1. a) Probability distribution of untransformed movement distances (in $250 \mathrm{~m}$ bins), b) probability distribution of $\log _{10}$-transformed movement distances (in $1 \mathrm{u}$. bins), and c) regression of $\log _{10}$-transformed movement distances against $\log _{10}$-transformed lag time, the number of days elapsed between encounters, for $n=6,279$ movement distances performed by $N=1,441$ individual Fowler's Toads, Anaxyrus fowleri, at Long Point, Ontario (2002 - 2021, incl) over lag times ranging from 1 to 86 days. F: adult females, $n$ $=2,696 ;$ M: adult males, $n=1,163 ; \mathrm{J}$ : juveniles, $n=2,420$.

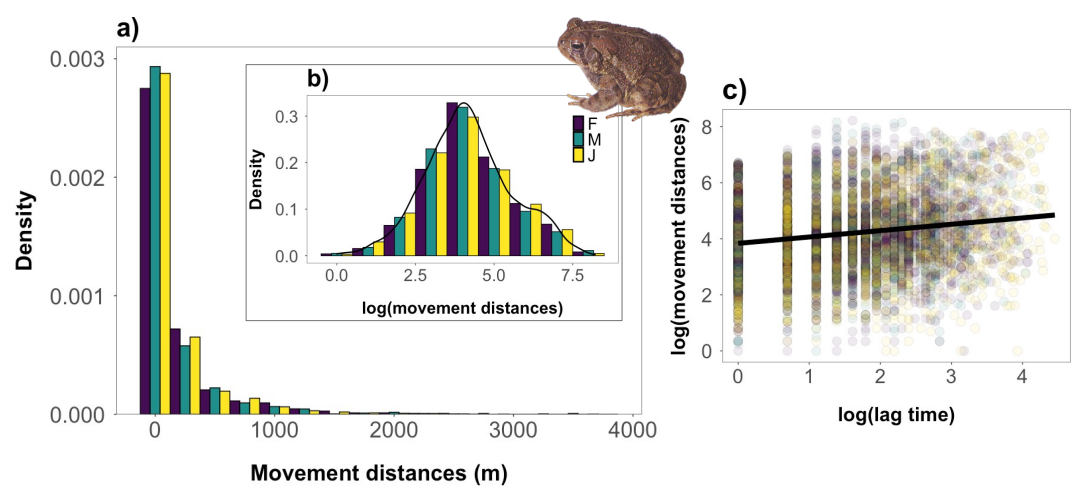

Figure 2. Water levels in Lake Erie in comparison to movement distances performed by Fowler's Toads, Anaxyrus fowleri, at Long Point, Ontario. a) Annual standard deviations $(\sigma)$ in $\log _{10}$-transformed daily toad movement distances (orange, dashed line) and in monthly maximum Lake Erie water levels (blue, dotted line) for each year from 2002 to 2021 (incl). b) Correlation between $\sigma_{\log _{10} \text { (movement distances) }}$ and $\sigma_{\text {lake level }}$ ( $n=20$ years), with linear regression fit obtained from model with predictors $\sigma_{\text {air temperature }}$ and $\sigma_{\text {lake level }}$. 
a)

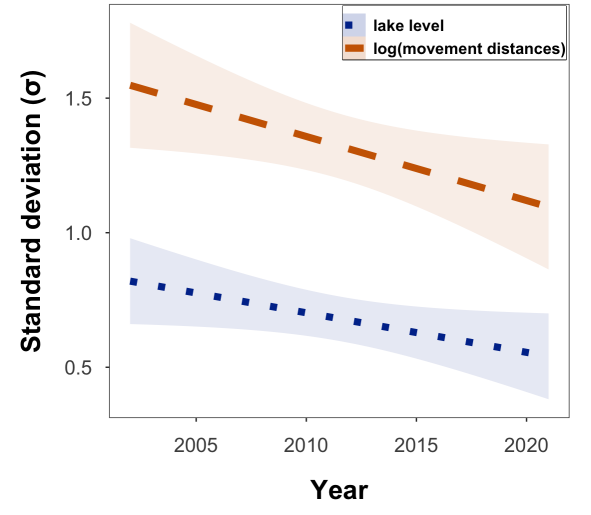

b)

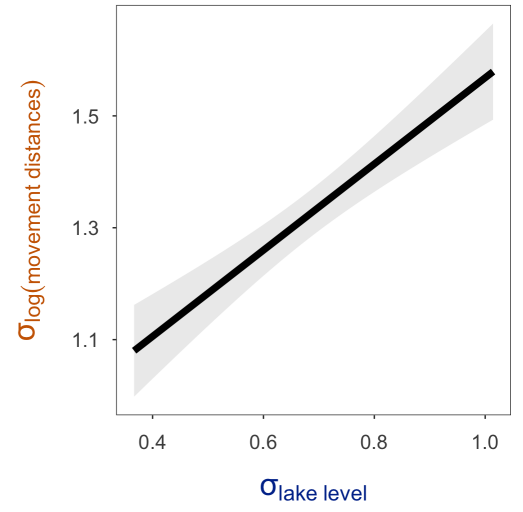

